\title{
Effect of High Fat vs. High Carbohydrate Feeding on the Development of Obesity in Weanling ob/ob Mice
}

\author{
S. M. Genuth \\ Saltzman Institute for Clinical Investigation, Mt. Sinai Hospital of Cleveland Case Western Reserve Univ. Cleveland, Ohio
}

Summary. Mice with hereditary obesity $(o b / o b)$ were fed isocaloric, isoprotein diets with varying proportions of carbohydrate-to-fat from the time of weaning to 18 weeks of age. Body weight, plasma glucose, and plasma insulin were determined at frequent intervals; body lipid and pancreatic insulin were determined at termination. Obesity developed when only carbohydrate was provided as caloric source (and in the presence of essential fatty acid deficiency), but obesity was greatly enhanced when $5 \%$ fat was added. Obesity also developed in the absence of dietary carbohydrate, even though hyperinsulinism was significantly reduced by this regimen. It is concluded that 1) both enhanced storage of dietary fat and lipogenesis contribute to obesity, the former more so than the latter; 2) the degree of hyperinsulinism does not determine the degree of obesity; 3) the development of hyperinsulinism does not require stimulation by exogenous oral carbohydrate.

Key words: Obesity, hyperinsulinism, insulin, diet, fat, carbohydrate.

A syndrome of genetic obesity in mice $(o b / o b)$ inherited as an autosomal recessive trait and accompanied by hyperglycemia, hyperinsulinism, and insulin resistance has been the subject of extensive investigation [ 1 , $2,3,4,5,6,7]$. The pathogenesis of obesity in these mice has, however, yet to be fully elucidated. Although hyperphagia is noted on ad lib diet $[8,9,10]$, an increased percentage of body fat persists even though progressive weight gain is prevented or body weight is actually reduced by food restriction $[9,10$, 11]. Qualitative differences in caloric intake may also affect lipid accumulation inasmuch as a high fat diet further enhances obesity when it is provided after the syndrome is already fully established [12]. The presence of greatly elevated fasting and post-glucose plasma levels of insulin - a lipogenic hormone - can also be postulated to play a role in the development of the $o b / o b$ syndrome.

The purpose of the present study was to determine the effect of feeding isocaloric, isoprotein diets with drastically altered carbohydrate/fat ratios to $o b / o b$ mice at an early age. In contrast to previously reported dietary studies, these differing caloric sources were made available to the mice prior to weaning and before obesity is obviously established. In this way, it was hoped to determine the influence of diet on the early development rather than simply the maintenance of obesity. At the same time, the effect of diet on the emergence of hyperinsulinism and its relationship to obesity could also be studied.

\section{Materials and Methods}

Weanling $o b / o b$ mice and their lean litter mates were obtained from the Jackson Memorial Laboratories, Bar Harbor, Maine. They were shipped at 15 to 17 days of age with foster mothers. At this age, the $o b / a b$ mice cannot be reliably distinguished from their litter mates, so all mice were individually numbered by earlobe puncture and randomly assigned to two groups. They were placed in cages with the foster mothers and two contrasting diets were immediately made available, one to each group as well as to the respective foster mothers. The mice generally continued to nurse for about one week, but when weaning appeared complete, the foster mothers were removed. The mice were then housed together in groups of three to four, separated by sex. They continued to feed ad lib on their respective diets for a total of 16 weeks. 
They were weighed weekly and morning heparinized blood was obtained at 1 or 2 week intervals by retrobulbar puncture for plasma glucose [7] and plasma insulin [13] determination. After 16 weeks, all $o b / o b$ and approximately equal numbers of lean mice were sacrificed by decapitation. A final blood sample and a sample of pancreas for insulin content [6] was obtained and the total lipid content of the carcass was determined [14]. For each week, the mean weight, plasma glucose and plasma insulin of the $o b / o b$ and lean mice was calculated retrospectively after it became obvious by visual inspection which mice proved to be the $o b / a b$. The overall mean plasma glucose and insulin for the entire experiment was then calculated for $a b / o b$ and lean mice in each dietary group from their weekly means. Statistical comparison was by Student's t test.

All test diets were isocaloric and specially formulated in powder form by Nutritional Biochemical Corporation to contain $20 \%$ casein as protein source, $4 \%$ complete salt and vitamin mixture, and sufficient alphacell as filler to yield a final caloric density of approximately 3.5 kilo calories/gram. Carbohydrate was added exclusively as glucose, and fat was added exclusively as cottonseed oil. The diets were color-coded and kept refrigerated throughout the experiment.

Three experiments were carried out over a one-year period, so seasonal variation may have influenced the final weights achieved. In each of the three experiments, one group received a $0 \%$ carbohydrate, $30 \%$ fat diet. This was then compared to $66 \%$ carbohydrate, $0 \%$ fat in Experiment A, to $64 \%$ carbohy- drate, $1 \%$ fat in Experiment B, and to 55\% carbohydrate, $5 \%$ fat in Experiment $C$. In each experiment, the diets appeared to be accepted by $o b / o b$ and lean mice, though accurate daily food intakes were not recorded. During Experiment A, clinical signs of essential fatty acid deficiency developed in both lean and $o b / o b$ mice receiving the $66 \%$ carbohydrate, $0 \%$ fat diet. These consisted of loss of fur and dermatitis, and several lean mice died before the conclusion of the experiment.

\section{Results}

Fig. 1 summarizes the change in body weight during the three experiments. Obese $(o b / o b)$ mice showed accelerated weight gain on $0 \%$ carbohydrate, $30 \%$ fat in all experiments, demonstrating that their obesity was not dependent on exogenous carbohydrate. In fact, when carbohydrate was the sole source of nonprotein calories $(66 \%$ carbohydrate, $0 \%$ fat diet - Fig. $1 \mathrm{~A})$, the weight gain of $o b / o b$ mice was markedly reduced, though not to the level of lean mice on the same fat-free diet. The isocaloric addition of only $1 \%$ fat to the diet increased considerably the rate at which $o b / o b$ mice gained weight (Fig. 1B), while the addition of $5 \%$ fat produced a rate of weight gain almost equal to that of the $o b / o b$ mice receiving $30 \%$ fat in the same experiment (Fig. 1C). Lean mice consistently grew well on the $0 \%$ carbohydrate, $30 \%$ fat intake. When lean mice received a $0 \%$ fat, $66 \%$ carbohydrate intake, weight gain ceased after six weeks as described
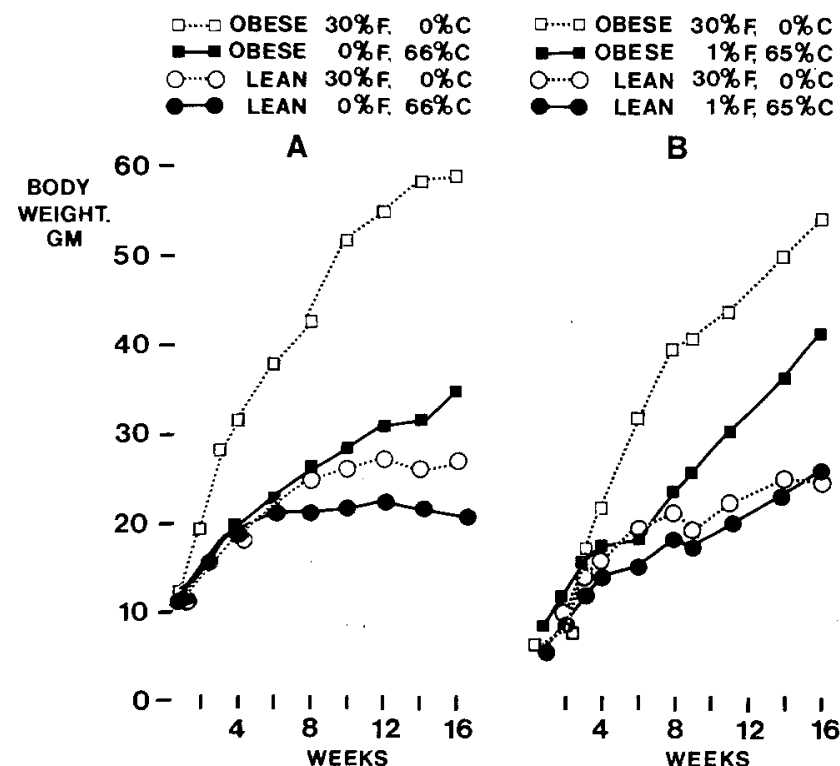

口...- $\square$ OBESE $30 \% \mathrm{~F}, \quad 0 \% \mathrm{C}$

$\longrightarrow$ OBESE $5 \%$ F $55 \%$

$O$ LEAN $30 \% \mathrm{~F}, 0 \% \mathrm{C}$

LEAN $5 \% \mathrm{~F}, 55 \% \mathrm{C}$

C
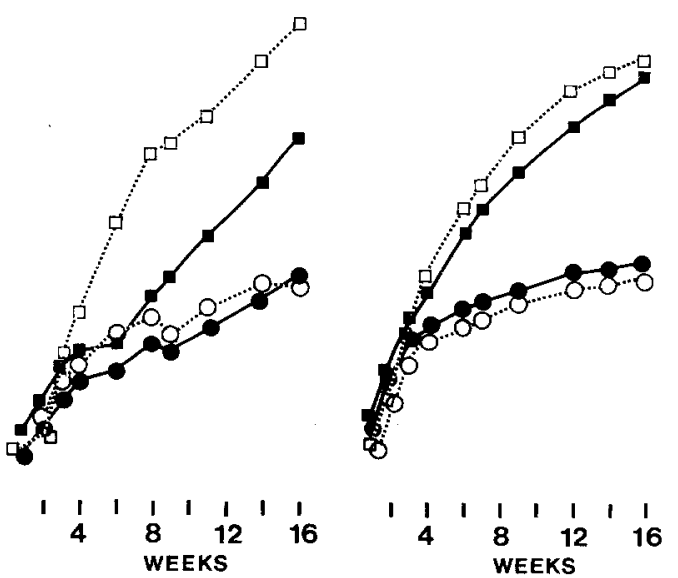

Fig. 1. Mean body weight measurements in $o b / o b$ mice (squares) and lean litter mates (circles) fed the indicated diets ad lib for 16 weeks. Each experiment was begun at 15-17 days of life 
by White et al. [15], presumably reflecting essential fatty acid deficiency. Both $1 \%$ and $5 \%$ isocaloric fat supplementation restored weight gain of lean mice to the level observed with $30 \%$ fat and eliminated clinical signs of essential fatty acid deficiency.

Analysis of body lipids in each experiment is shown in Table 1. Regardless of the proportion of fat and carbohydrate in the diet, the percentage of body weight as lipid in $o b / o b$ mice was greatly increased, ranging from $41 \%$ to $50 \%$ compared to $10 \%$ to $17 \%$ in lean mice. The $0 \%$ fat, $66 \%$ carbohydrate diet resulted in a 24-gram reduction in final body weight of $o b / o b$ mice, but only one-half of the deficit was accounted for by lipid. Thus, it may be presumed that lean body mass was also greatly reduced in these $a b / o b$ mice, possibly as a consequence of essential fatty acid deficiency. When only $1 \%$ fat was added to the diet, the deficit in final body weight was reduced to 13 grams, nearly four-fifths of which was accounted for by lipid. This suggested that lean body mass was nearly restored, while the degree of obesity remained restricted on an intake of $1 \%$ fat. With 5\% dietary fat, both body weight and body lipid became essentially equal to that of $o b / o b$ mice on a $30 \%$ fat intake. In lean mice on a $0 \%$ fat, $66 \%$ carbohydrate diet, less than one-fifth of the final body weight deficit was attributed to a decrease in lipid, indicating a large relative reduction in lean body mass. Addition of $1 \%$

Table 1. Final body weight and body lipid in obese and lean mice fed varying proportions of fat and carbohydrate from 18 days to 18 weeks of life

$\begin{array}{lll}\text { Body weight, } & \text { Body Lipid, } & \text { Body Lipid } \\ \text { GM } \Delta & \text { GM } & \begin{array}{l}\text { Body Weight } \\ \%\end{array}\end{array}$

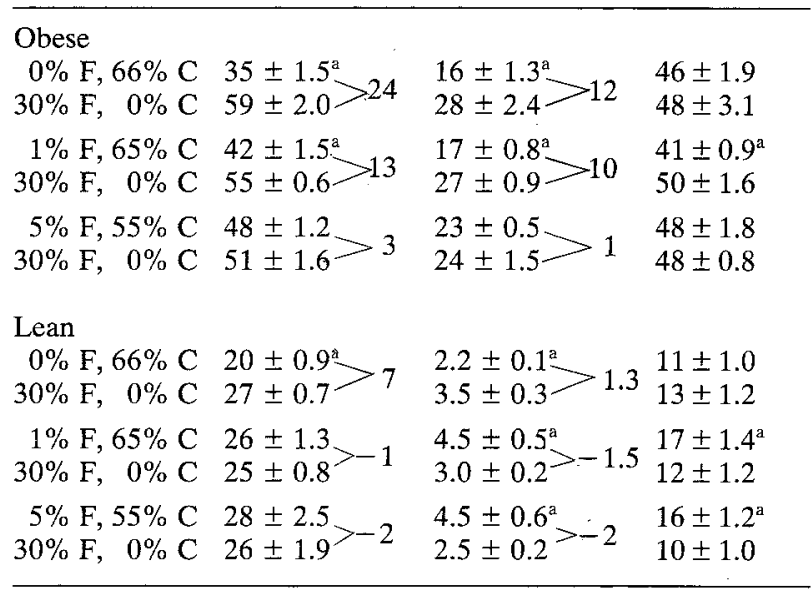

mean \pm SEM

$\mathbf{n}=5-8$ Mice per group

$F=$ Fat as cottonseed oil

$\mathrm{C}=$ Carbohydrate as glucose

$\mathrm{a}=\mathrm{p}<0.025-<0.001$ comparing diets or $5 \%$ fat equalized weight gain relative to the $30 \%$ fat intake and actually led to a slightly but significantly greater degree of lipid accumulation.

Table 2 shows the prevailing plasma glucose and plasma insulin values throughout each experiment as well as the pancreatic insulin content at termination. In $o b / o b$ mice, plasma insulin was significantly lower in all three groups receiving $0 \%$ carbohydrate than in the paired groups receiving $55 \%$ to $66 \%$ carbohydrate. Pancreatic insulin was reduced in parallel approximately one-half, though this was statistically significant only in two of the three experiments. Lean mice also had significantly lower plasma insulin levels on $0 \%$ carbohydrate intake, but demonstrated less reduction in pancreatic insulin. In all experiments and on each diet, plasma and pancreatic insulin of $o b / o b$ mice greatly exceeded that of lean mice, as previously reported $[4,5,6]$. Variation of plasma glucose was relatively minor with different diets. Obese $(o b / o b)$ mice always had slightly greater mean glucose levels than lean mice during the 16 weeks of each experiment, but this was only noteworthy in Experiment A where $o b / o b$ mice on $0 \%$ fat, $66 \%$ carbohydrate diet had significant hyperglycemia relative to lean mice on the same diet and relative to $o b / o b$ mice on $0 \%$ carbohydrate, $30 \%$ fat.

Table 2. Plasma glucose, plasma insulin and pancreatic insulin in obese and lean mice fed varying proportions of fat and carbohydrate from 18 days to 18 weeks of life

\begin{tabular}{|c|c|c|c|}
\hline & $\begin{array}{l}\text { Plasma } \\
\text { Glucose, } \\
\text { MG/100 ML }\end{array}$ & $\begin{array}{l}\text { Plasma } \\
\text { Insulin, } \\
\mu U \text { Units/ML }\end{array}$ & $\begin{array}{l}\text { Pancreatic } \\
\text { Insulin, } \\
\text { Units/GM }\end{array}$ \\
\hline \multicolumn{4}{|l|}{ Obese } \\
\hline $0 \% \mathrm{~F}, 66 \% \mathrm{C}$ & $192 \pm 10^{\mathrm{a}}$ & $940 \pm 224^{a}$ & $13.9 \pm 7.2$ \\
\hline $30 \% \mathrm{~F}, \quad 0 \% \mathrm{C}$ & $133 \pm 6$ & $307 \pm 40$ & $7.2 \pm 0.7$ \\
\hline $1 \% \mathrm{~F}, 65 \% \mathrm{C}$ & $132 \pm 10$ & $587 \pm 104^{a}$ & $25.7 \pm 4.7^{\mathrm{a}}$ \\
\hline $30 \% \mathrm{~F}, \quad 0 \% \mathrm{C}$ & $149 \pm 6$ & $176 \pm 31$ & $10.4 \pm 0.7$ \\
\hline $5 \% \mathrm{~F}, 55 \% \mathrm{C}$ & $162 \pm 9$ & $347 \pm 53^{\mathrm{a}}$ & $16.3 \pm 2.2^{\mathrm{a}}$ \\
\hline $30 \% \mathrm{~F}, \quad 0 \% \mathrm{C}$ & $163 \pm 7$ & $109 \pm 17$ & $8.1 \pm 0.9$ \\
\hline \multicolumn{4}{|l|}{ Lean } \\
\hline $0 \% \mathrm{~F}, 66 \% \mathrm{C}$ & $128 \pm 9$ & $95 \pm 14^{a}$ & $8.2 \pm 1.8$ \\
\hline $30 \% \mathrm{~F}, \quad 0 \% \mathrm{C}$ & $125 \pm 6$ & $33 \pm 5$ & $6.2 \pm 1.5$ \\
\hline $1 \% \mathrm{~F}, 65 \% \mathrm{C}$ & $112 \pm 2$ & $50 \pm$ & $6.3 \pm 0.4^{a}$ \\
\hline $30 \% \mathrm{~F}, \quad 0 \% \mathrm{C}$ & $130 \pm 8$ & $19 \pm$ & $4.6 \pm 0.5$ \\
\hline $5 \% \mathrm{~F}, 55 \% \mathrm{C}$ & $140 \pm 5$ & $65 \pm$ & $6.6 \pm 1.1$ \\
\hline $30 \% \mathrm{~F}, \quad 0 \% \mathrm{C}$ & $147 \pm 5$ & $23 \pm$ & $3.9 \pm 0.7$ \\
\hline
\end{tabular}

mean \pm SEM Each group of 5-8 mice was sampled at 1-3 week intervals and a mean determined for that sampling. The plasma values in the table are the mean \pm SEM of 9-11 such weekly sampling means.

$\mathrm{F}=$ Fat as cottonseed oil

$\mathrm{C}=$ Carbohydrate as glucose

$\mathrm{a}=\mathrm{p}<0.025-<0.001$ Comparing diets 


\section{Discussion}

The major points which this study makes are as follows. 1) Obese (ob/ob) mice can develop a degree of obesity even in the complete absence of dietary fat from the time of weaning (Experiment A). When compared to lean mice similarly restricted, this was true both in the relative sense (increased percentage of body fat) and in the absolute sense (increased total body fat). Thus, enhanced lipogenesis from carbohydrate and protein must be one factor in the production of their obesity. Both the liver and adipose tissue may be sites of this accelerated lipogenesis. 2) Obese $(o b / o b)$ mice can become obese even under unfavorable nutritional circumstances from the time of weaning. The $0 \%$ fat diet clearly retarded growth of lean body mass in both $o b / o b$ mice and lean litter-mates, and produced clinical signs of essential fatty acid deficiency. This nutritional deprivation affected lean and $a b / o b$ mice similarly in that each retained the same percentage of body lipid as was observed in the respective paired group on a $30 \%$ fat intake. 3) Obese $(o b / o b)$ mice can also become obese in the complete absence of dietary carbohydrate, as shown.in all three experiments. Though protein was still available as a carbon source for lipogenesis, it is unlikely that obesity could have resulted entirely from conversion of protein to fat inasmuch as there was no evidence of reduction in the lean body mass of $o b / a b$ mice on $0 \%$ carbohydrate, $30 \%$ fat, compared to those on $55 \%$ carbohydrate, $5 \%$ fat (Experiment $\mathrm{C}$ ). Body weights and body lipids in these two groups were essentially equal. Thus, in $o b / o b$ mice, obesity must also result in part from storage of dietary fat, as demonstrated directly by Lemonnier et al. [12]. Indeed, it seems likely that this may be the major factor in the development of their obesity. When a limited amount of high quality fat was provided, sufficient to eliminate obvious evidence of essential fatty acid deficiency $(1 \%$ fat, $65 \%$ carbohydrate diet, Experiment B), the accumulation of body fat was still greatly restricted even though a surfeit of carbohydrate calories was available for lipogenesis. This restriction could in part also have reflected a subclinical degree of essential fatty acid deficiency. Supplementation of the diet with $5 \%$ fat permitted full development of obesity since body lipid became equal to that of $o b / o b$ mice fed $30 \%$ fat. Thus, the complete exhibition of obesity appears to require the presence of, and up to a point may be proportional to, dietary fat content. The importance of dietary fat in the genesis of obesity is enhanced by previous observations that $o b / a b$ mice with established obesity tend to choose more fat than lean controls when allowed to select caloric sources [8] and that high fat diets do not depress lipogenesis in their adipose tissue $[12,16]$.
Thus, it is not surprising that allowed free access to a high-fat diet from the time of weaning, obesity would occur more readily in $o b / o b$ mice. Indeed, this phenomenon has also been demonstrated in normal weanling mice [17]. 4) The degree of obesity in $o b / o b$ mice does not depend directly on prevailing insulin levels alone. Though $o b / o b$ mice developed and maintained hyperinsulinism on all of the dietary intakes, consistently greater stimulation of insulin release and storage was produced by provision of all non-protein calories as carbohydrate, as has also been noted in studies with older $o b / o b$ mice $[12,18]$. However, this never resulted in greater relative or absolute obesity. That hyperinsulinism may not be an obligatory factor in the genesis of obesity in $o b / o b$ mice has also been suggested by the fact that reduction of insulin levels to or toward those of lean controls by pharmacologic damage to the B-cells does not alter body weight [19]. Some insulin could, of course, be required in a permissive manner to allow enhanced lipid synthesis or storage, in this respect acting as it does in lean mice. The present results are also in accord with others which indicate that hyperinsulinism is a secondary and not a primary phenomenon in the pathogenesis of the $a b / o b$ syndrome $[5,7,20,21]$. Furthermore, hypersecretion of insulin does not appear dependent on stimulation by exogenous oral carbohydrate inasmuch as* $o b / o b$ mice on carbohydrate-free intakes still developed elevated plasma and pancreatic insulin levels post-weaning. Hyperinsulinism could well be secondary to obesity itself. However, transplantation of normal islets into $o b / o b$ mice has been reported to ameliorate both their obesity and hyperinsulinism [22] and parabiosis with normal mice reduces their food intake and obesity [23]. Therefore, both hyperinsulinism and obesity may be interdependent effects of a primary disorder in an islet-hypothalamic axis as yet uncharacterized.

Acknowledgements. This study was supported by NIH Grant AM 10290.

\section{References}

1. Ingalls, A. M., Dickie, M. M., Snell, G. D.: Obese, a new mutation in the house mouse. J. Hered. 41, 317-318 (1950)

2. Mayer, J., Russell, R. E., Bates, M. W., Dickie, M. M.: Metabolic, nutritional and endocrine studies of the hereditary obesity-diabetes syndrome of mice and mechanism of its development. Metabolism 2, 9-21 (1953)

3. Stauffacher, W., Crofford, O. B., Jeanrenaud, B., Renold, A. E.: Comparative studies of muscle and adipose tissue metabolism in lean and obese mice. Ann. N. Y. Acad. Sci. 131, 528-540 (1965)

4. Stauffacher, W., Lambert, A. E., Vecchio, D., Renold, A. E.: Measurements of insulin activities in pancreas and serum of mice with spontaneous ("Obese" and "New Zealand Obese") 
and induced (goldthioglucose) obesity and hyperglycemia, with considerations on the pathogenesis of the spontaneous syndrome. Diabetologia 3, 230-237 (1967)

5. Westman, S.: Development of the obese-hyperglycemic syndrome in mice. Diabetologia 4, 141-149 (1968)

6. Genuth, S. M.: Hyperinsulinism in mice with genetically determined obesity. Endocrinology 84, 386-391 (1969)

7. Genuth, S. M., Przybylski, R. J., Rosenberg, D. M.: Insulin resistance in genetically obese, hyperglycemic mice. Endocrinology 88, 1230-1238 (1971)

8. Mayer, J., Dickie, M. M., Bates, M. W., Vitale, J. J.: Free selection of nutrients by hereditarily obese mice. Science 113, 745-746 (1951)

9. Alonso, L. G., Maren, T. H.: Effect of food restriction on body composition of hereditary obese mice. Amer. J. Physiol. 183, 284-290 (1955)

10. Welton R. F., Martin, J. R., Baumgardt, B. R.: Effects of feeding and exercise regimens on adipose tissue glycerokinase activity and body composition of lean and obese mice. J. Nutr. 103, 1212-1220

11. Chlouverakis, C.: Effect of caloric restriction on body weight loss and body fat utilization in obese hyperglycemic mice (obob). Metabolism 21, 10-17 (1972)

12. Lemonnier, D., Winand, J., Furnelle, J., Christophe, J.: Effect of a high-fat diet on obese-hyperglycaemic and non-obese Bar Harbor mice. Diabetologia 7, 328-333 (1971)

13. Genuth, S. M., Lebovitz, H. E.: Stimulation of insulin release by corticotropin. Endocrinology 76, 1093-1099 (1965)

14. Kramer, M. W., Liberman, D. F., Soeldner, J. S., Gleason, R. E.: Dissociation of hyperglycaemia and obesity in mice fed high fat diets. Diabetologia 5, 353-355 (1969)

15. White, E. A., Foy, J. R., Cerecedo, L. R.: Essential fatty acid deficiency in the mouse. Proc. Soc. exp. Biol. (N. Y.) 54, 301-307 (1943)

16. Lochaya, S., Leboeuf, N., Mayer, J., Leboeuf, B.: Adipose tissue metabolism of obese mice on standard and high-fat diets. Amer. J. Physiol. 201, 23-26 (1961)

17. Lemonnier, D.: Effect of age, sex and site on the cellularity of the adipose tissue in mice and rats rendered obese by a high fat diet. J. clin. Invest. 51, 2907-2915 (1972)

18. Chlouverakis, C.: On the origin of hyperglycaemia in the obesehyperglycaemic mouse $(o b o b)$ : Effect of diet on blood glucose and serum insulin in $o b o b$ and gold-thioglucose obese mice. Diabetologia 7, 373-378 (1971)

19. Mahler, R. J., Szabo, O.: Amelioration of insulin resistance in obese mice. Amer. J. Physiol. 221, 980-983 (1971)

20. Chlouverakis, C., Dade, E. F., Batt, R. A. L.: Glucose tolerance and time sequence of adiposity, hyperinsulinemia and hyperglycemia in obese hyperglycemic mice $(o b o b)$. Metabolism 19, 687-693 (1970)

21. Joosten, H. F. P., van der Kroon, P. H. W.: Enlargement of epididymal adipocytes in relation to hyperinsulinemia in obese hyerglycemic mice $(o b / o b)$. Metabolism 23, 59-66 (1974)

22. Strautz, R. L.: Studies of hereditary-obese mice ( $o b o b)$ after implantation of pancreatic islets in millipore filter capsules. Diabetologia 6, 306-312 (1970)

23. Coleman, D. L.: Effects of parabiosis of obese with diabetes and normal mice. Diabetologia 9, 294-298 (1973)

Received: October 14, 1975, and in revised form: January 29, 1976

S. M. Genuth, M. D.

Director

Saltzman Institute for

Clinical Investigation

The Mt. Sinai Hospital of Cleveland

Univ. Circle

Cleveland, Ohio 44106

USA 